\title{
Pengaruh Lama Fermentasi Terhadap Nilai Angka Lempeng Total \& Kapang Pada Kopi Robusta Lampung (Coffea Canephora)
}

\author{
Effect of Fermentation Time Against Total Plate Numbers \& Molds in Lampung Robusta \\ Coffee (Coffea canephora)
}

\author{
Damar wiraputra, Rizki adrianto, Fidela Devina Agrippina, Masmulki Daniro Jyoti \\ Balai Riset dan Standardisasi Industri Bandar Lampung \\ Jl by pass Soekarno Hatta KM 1 Rajabasa \\ E-mail : Damar.wiraputra@gmail.com
}

\begin{abstract}
Abstrak
Kopi merupakan salah satu komoditas yang digemari oleh konsumen. Fermentasi biji kopi merupakan cara pengolahan biji kopi secara basah yang berperan dalam pembentukan senyawa prekusor pembentuk citarasa kopi. Namun selain citarasa salah satu kriteria mutu produk kopi yaitu mutu mikrobiologi. Mutu mikrobiologi dapat diidentifikasi melalui beberapa pengujian untuk mengetahui jumlah cemaran mikroba di dalam produk, di antaranya uji Angka Lempeng Total (ALT) dan Angka Kapang. Penelitian ini dilakukan untuk melihat pengaruh lama fermentasi biji kopi terhadap Angka Lempeng Total (ALT) dan kapang pada produk biji kopi Robusta Lampung. Perlakuan lama fermentasi biji kopi robusta Lampung dilakukan dengan perlakuan lama fermentasi sebanyak 4 perlakuan yaitu: perlakuan A (0 jam), B (8 jam), C (16 jam) dan D (24 jam). Berdasarkan hasil penelitian kopi fermentasi $D$ (lama fermentasi 24 jam) mempunyai nilai ALT paling banyak yaitu sebanyak 180 gram/koloni. Sedangkan hasil analisa pertumbuhan kapang paling tinggi diperoleh pada perlakuan $B$ (lama fermentasi 8 jam) yaitu sebanyak $7 \mathrm{gram} / \mathrm{koloni}$.
\end{abstract}

Kata kunci: Fermentasi, Kopi Robusta, ALT, Kapang

\begin{abstract}
Coffee is a commodity that is favored by consumers. Coffee bean fermentation is a way of processing coffee beans wet which plays a role in the formation of precursor compounds forming coffee flavor. But besides taste one of the criteria for the quality of coffee products is microbiological quality. Microbiological quality can be identified through several tests to find out the amount of microbial contamination in the product, including the Total Plate Count (TPC) test and Mold Figures. This research was conducted to see the effect of coffee bean fermentation time on the Total Plate Number and mold on Robusta Lampung coffee bean products. The length of fermentation treatment of Robusta coffee beans was carried out with 4 treatments of fermentation time, namely: A (0 hour), B (8 hour), C (16 hour) and D (24 hour) treatment. Based on research results $D$ fermented coffee (24-hour fermentation time) has the most TPC value, which is $180 \mathrm{gram} /$ colony. While the results of the highest mold growth analysis were obtained in treatment $B$ ( 8 hours fermentation time), which is as much as 7 grams/colony.
\end{abstract}

Keywords: Fermentation, Robusta Coffee, TPC, Mold.

\section{Pendahuluan}

Provinsi Lampung merupakan salah satu provinsi yang sumber pendapatannya sebagian besar dari hasil perkebunan. Komoditas hasil perkebunan yang dihasilkan oleh Lampung diantaranya adalah kopi Robusta. Komoditas tersebut selanjutnya diolah menjadi berbagai macam produk antara ataupun hilir seperti kopi bubuk.
Kopi Robusta merupakan hasil perkebunan masyarakat di provinsi Lampung. Menurut data Kementan, 2015 provinsi ini menjadi salah satu sentra produksi kopi Robusta terbesar pertama di Indonesia dengan persentase sebesar 27,93\% dari total keseluruhan produksi nasional. Hal ini menjadikan provinsi Lampung memiliki potensi yang cukup besar untuk meningkatkan pembangunan ekonomi melalui ekspor produk biji kopi Robusta unggulan. Produksi kopi 
Robusta di Lampung terpusat di Kabupaten Lampung Barat sebesar 41,38\%, Kab Tanggamus sebesar 24,16\%, dan Kabupaten Way Kanan sebesar 13,73\% (PDSIP, 2015).

Konsumsi kopi dalam negeri cenderung meningkat tiap tahun sebesar $6-8 \%$. Hal ini disebabkan karena pertumbuhan industri kedai kopi yang berkembang pesat. Jumlah konsumsi kopi berdasarkan survei LPEM UI mencapai 800g/kapita/tahun (Ditjen PPHP, 2012; Asosiasi Eksportir Kopi Indonesia, 2012).

Masyarakat umum mengonsumsi kopi karena citarasa dan pengaruh terhadap fisiologis tubuh yang dapat menyebabkan tubuh terasa tetap terjaga, membuat tubuh segar, berkurangnya rasa lelah dan lebih bersemangat dan bukan karena nilai gizinya (Atmawinata, 2002).

Citarasa kopi merupakan hal yang sangat penting karena menentukan mutu serta kualitas biji kopi yang diproduksi. Biji kopi yang berkualitas baik dapat diperoleh melalui proses pengolahan, diantaranya proses fermentasi dan penyangraian (Pimenta et al., 2009; Budryn et al., 2011 and Wang, 2012).

Pengolahan kopi dapat dilakukan dengan cara pengolahan basah (Sulistyaningtyas, 2017), pengolahan kopi kering (Choiron, 2010), dan pengolahan semi basah (Barlaman, 2013). Fermentasi pada biji kopi dapat dilakukan baik secara alami dan secara tambahan kultur bakteri. Penambahan kultur bakteri dilakukan pada fermentasi biji kopi metode semi basah dengan tujuan untuk mengurangi penggunaan air yang banyak pada proses pengolahan fermentasi biji kopi metode lainnya sehingga mempercepat proses fermentasi agar citarasa produk kopi yang dihasilkan lebih maksimal.

Aspek mikrobiologi tidak dapat diabaikan dari suatu produk. Keberadaan mikroorganisme dapat memengaruhi mutu dan keamanan produk pangan sehingga perlu ditetapkan batasbatas wajar yang aman dan terkendali untuk menghasilkan produk pangan bermutu, tak terkecuali bagi produk kopi.

Selain itu, syarat kualitas biji kopi diantaranya biji kopi tidak ada yang berbau busuk, tidak tumbuh kapang. Bau busuk tersebut terjadi karena terdapat kontaminasi dari kapang setelah tahap pascapanen yaitu pada tahao penyimpanan (Apriliana, 2017).

Menurut Yoni (2016), daya tahan, resiko kontaminasi serta jaminan keamanan pangan digunakan sebagai standar mikrobiologi. Serta menjadi indicator kebersihan atau higienitas bahan baku sampai menjadi produk jadi dari setiap tahapan proses produksi. Hal tersebut dikarenakan apabila produk pangan terkontaminasi bakteri, maka seseorang yang mengonsumsi suatu makanan tersebut dapat terserang berbagai penyakit.

Standar mikrobiologi pada produk kopi instan dapat digunakan untuk mengantisipasi rendahnya suatu kondisi sanitasi dan higienitas proses produksi kopi instan di Indonesia, terutama setelah proses spraying. Jenis mikroba yang dapat ditentukan adalah Angka Lempeng Total (ALT) dan kapang (Martoyo, Haryadi dan Rahayu, 2014).

Kriteria cemaran mikroba kopi bubuk diatur dalam SNI 7388:2009 yaitu angka lempeng total (ALT) $1 \times 10^{6} \mathrm{koloni} / \mathrm{g}$ dan kapang $1 \times 10^{4} \mathrm{koloni} / \mathrm{g}$. Sedangkan, batas cemaran mikroba yang ditetapkan BPOM (2016) pada pemeriksaan ALT kopi bubuk maksimal $10^{6}$ koloni/ml dan kapang $10^{4} \mathrm{koloni} / \mathrm{ml}$.

Menurut Rasyidah (2018), hasil penelitiannya menunjukkan Angka Lempeng Total (ALT) kopi bubuk sebelum diseduh adalah $1,2 \pm 0,3 \times 10^{1}$ hingga $1,1 \pm 0,1 \times 10^{2}$ koloni/g dan total kapang $1,0 \times 10^{1}$ hingga $2,5 \pm 2,8 \times 10^{2}$ koloni/g. Sedangkan menurut Silva (2008) dikutip Martoyo, dkk (2014), buah kopi yang dilakukan proses fermentsai selama 22 hari dan dilakukan pengeringan, terdapat kandungan beberapa jenis bakteri dan kapang lebih dari $10^{4}$ koloni/g.

Hal ini menunjukkan belum banyak informasi mengenai penelitian tentang Angka Lempeng Total (ALT) dan Kapang pada kopi Robusta Lampung. Mengingat rentan terjadinya kontaminasi pada biji kopi Robusta, maka perlu dilakukan pemeriksaan Angka Lempeng Total (ALT) dan Kapang pada biji Kopi Fermentasi Robusta di Lampung.

Menilai hal tersebut perlu dilakukan penelitian mengenai lama fermentasi biji kopi robusta Lampung yang optimal terhadap Angka Lempeng Total (ALT) dan kapang, sehingga diharapkan menghasilkan produk kopi yang sesuai keinginan konsumen yaitu produk bercitarasa unggul dan memiliki nilai tambah tinggi.

\section{Metode Penelitian}

\section{Alat dan Bahan}

Alat-alat yang digunakan dalam penelitian ini adalah autoklaf, Bunsen, cawan petri, gelas beaker, erlenmeyer, hot plate, inkubator, Biosafety cabinet (BSC), mikro pipet, 
pipet ukur, tabung reaksi, timbangan analitik, vortex,

Bahan-bahan yang digunakan adalah akuades, alkohol, media Buffered Peptone Water (BPW), media Plate Count Agar (PCA), media Potato Dextrose Agar (PDA), dan sampel kopi bubuk yang telah di fermentasi.

\section{Cara Kerja}

Sampel ditimbang sebanyak 1 gram lalu masukan sampel ke dalam tabung reaksi yang sudah diisi $9 \mathrm{ml}$ media BPW (suspensi) sebagai pengenceran $10^{-1}$, selanjutnya $1 \mathrm{ml}$ larutan diambil dan larutan itu dimasukkan ke dalam tabung reaksi yang berisi $9 \mathrm{ml}$ media BPW (10-2) dihomogenkan, kemudian di ambil $1 \mathrm{ml}$ dan di masukkan ke dalam tabung reaksi yang berisi 9 $\mathrm{ml}$ media BPW $\left(10^{-3}\right)$ dan ulangi perlakuan dengan cara kerja yang sama sampai pengenceran $10^{-4}$. Selanjutnya masing-masing pengenceran diambil sebanyak $1 \mathrm{ml}$ dan masukan larutan tersebut ke cawan petri yang telah berisi $15 \mathrm{ml}$ media PCA untuk analisa ALT secara duplo dan media PDA untuk analisa Total Kapang, lalu dihomogenkan dan ditutup (Hartati, 2016), kemudian cawan berisi media PCA diinkubasi pada suhu $37^{\circ} \mathrm{C}$ selama 48 jam dan cawan berisi media PDA diinkubasi pada suhu $25^{\circ} \mathrm{C}$ selama 72 jam. Perhitungan untuk analisa ALT dilakukan hanya untuk pengenceran dengan jumlah koloni 30-300 dan untuk analisa kapang hanya pengenceran dengan jumlah 10150 koloni.

\section{Hasil Dan Pembahasan}

\section{Analisis Mikrobiologi}

Prinsip perhitungan mikrobiologis yaitu dengan menumbuhkan mikroorganisme pada medium agar dapat tumbuh dan membentuk suatu koloni untuk dapat diketahui suatu produk pangan mengandung mikroorganisme atau tidak (kualitatif) dan jumlah mikroorganisme tersebut (kuantitatif) (Fardiaz, 2004).

\section{Angka Lempeng Total (ALT)}

Angka Lenpeng Total (ALT) adalah pengujian yang digunakan dalam mengetahui jumlah mikroba secara kuantitatif suatu produk pangan dan banyak digunakan dikarenakan koloni yang terbentuk dapat dilihat langsung tanpa membutuhkan mikroskop. Menurut Yoni (2016), satuan koloni dinyatakan dalam unit per gram (cfu/gram) atau ml sampel. Analisa ALT mampu menghitung bakteri yang tumbuh dalam suhu inkubasi sekitar $30^{\circ}-37^{\circ} \mathrm{C}$ dengan oksigen yang tersedia. Prinsip dari angka lempeng total yaitu koloni bakteri aerob mesofil ditumbuhkan setelah dilakukan inokulasi pada media lempeng agar dengan metode pour plate (cara tuang) dan kemudian dilakukan inkubasi pada suhu yang tepat (Elliot,1978). Hasil analisa ALT dapat dilihat pada Tabel 1 berikut.

Tabel 1. Hasil Analisa ALT Kopi Robusta Lampung

\begin{tabular}{lcc}
\hline Variasi Kopi & $\begin{array}{c}\text { ALT } \\
\text { (koloni/g) }\end{array}$ & Baku mutu \\
\hline A (Fermentasi 0 jam) & $4 \times 10^{1}$ & $10^{6}$ \\
B (Fermentasi 8 jam) & $1.5 \times 10^{2}$ & $10^{6}$ \\
C (Fermentasi 16 jam) & $1.7 \times 10^{2}$ & $10^{6}$ \\
D (Fermentasi 24 jam) & $1.8 \times 10^{2}$ & $10^{6}$ \\
\hline
\end{tabular}

Dari Tabel 1 diperoleh bahwa ALT pada 4 sampel biji kopi hasil fermentasi seluruhnya memenuhi syarat SNI 7388:2009 serta Perka BPOM tahun 2016. ALT biji kopi hasil fermentasi terlihat antara $40 \mathrm{koloni} / \mathrm{g}$ hingga $180 \mathrm{koloni} / \mathrm{g}$. Hasil uji angka lempeng total pada seluruh sampel kopi fermentasi disajikan pada Gambar 1.

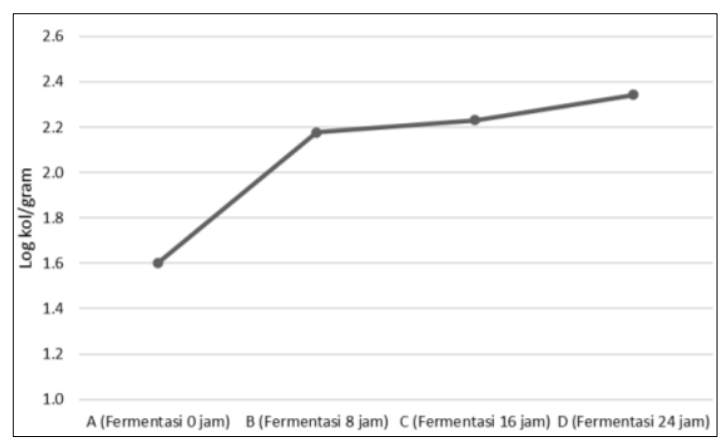

Gambar 1. Angka Lempeng Total (ALT) Biji Kopi Robusta Lampung Hasil Fermentasi

Secara standar, batasan cemaran mikroorganisme semua sampel kopi Robusta Lampung Fermentasi lebih rendah dari standar. Hasil Analisa Angka Lempeng Total (ALT) menunjukkan angka yang paling besar terdapat pada variasi kopi D (lama fermentasi 24 jam). yaitu sebesar 180 koloni/gram. Namun nilai tersebut menunjukkan biji kopi Robusta Fermentasi masih aman untuk dikonsumsi karena jumlah cemaran bakteri tidak melampaui batas yaitu $1 \times 10^{6} \mathrm{koloni} / \mathrm{g}$ seperti yang telah ditetapkan pada SNI dan Perka BPOM tentang kopi bubuk. 
(ALT) juga menunjukkan kecenderungan semakin meningkat selama waktu fermentasi yang dilakukan, hal demikian selama proses fermentasi terjadi pertumbuhan mikroba, aktifnya enzim-enzim, kemudian terjadi reaksi pencoklatan enzimatis dan ditandai saat fermentasi peningkatan suhu serta munculnya gelembung-gelembung saat proses fermentasi biji kopi robusta Lampung di dalam fermentor. (Yusianto dan Widyotomo, 2013).

Kecenderungan yang semakin meningkat pun menunjukkan nilai pertumbuhan mikroba yang ada. Menurut Ray (2004) dikutip Khairani (2017), tumbuhnya mikroba pada suatu bahan pangan diantaranya dipengaruhi oleh jumlah nutrisi tertentu yang tersedia dalam bahan sehingga jenis dan banyaknya mikroba yang tumbuh juga akan berbeda. Pengaruh nutrisi dari keberadaan ingredien tersebut diduga kuat sebagai salah satu penyebab signifikansi perbedaan jumlah koloni mikroba kopi bubuk dan instan.

\section{Kapang}

Pengujian Angka Kapang umumnya dilakukan dalam mengetahui munculnya cemaran kapang pada produk pangan yang diinkubasi dalam suhu ruang. Hitokoto \& Morazumi (1978), kapang maupun khamir yang tumbuh dapat dihitung setelah dilakukan inokulasi pada media yang tepat dengan suhu inkubasi $20^{\circ}-25^{\circ} \mathrm{C}$. Hasil analisa kapang kopi fermentasi robusta Lampung dapat dilihat pada Tabel 2.

Tabel 2. Hasil Analisa Kapang Kopi Robusta Lampung.

\begin{tabular}{lcc}
\hline Variasi Kopi & $\begin{array}{l}\text { Kapang } \\
\text { (koloni/g) }\end{array}$ & Baku Mutu \\
\hline A (Fermentasi 0 jam) & 0 & $10^{4}$ \\
B (Fermentasi 8 jam) & 7 & $10^{4}$ \\
C (Fermentasi 16 jam) & 5 & $10^{4}$ \\
D (Fermentasi 24 jam) & 3 & $10^{4}$ \\
\hline
\end{tabular}

Berdasarkan Tabel 2 di atas diperoleh hasil analisa kapang sebesar 0-7 koloni/gram dari setiap variasi lama fermentasi biji kopi Robusta Lampung yang memenuhi standar yang berlaku yaitu kurang dari $10^{4}$ koloni/gram sesuai standar SNI 7388:2009 serta Perka BPOM tahun 2016 yang ditetapkan berdasarkan cemaran mikroorganisme kapang. Secara standar, batasan cemaran mikroorganisme semua sampel kopi Robusta Lampung setelah fermentasi yang diuji lebih rendah dari standar atau dibawah $10^{1} \mathrm{koloni} /$ gram.

Pertumbuhan kapang umumnya berjalan lambat jika dibandingkan dengan pertumbuhan bakteri dan khamir. Jika kondisi pertumbuhan sesuai maka semua mikrorganisme dapat tumbuh, kapang biasanya cenderung kalah dalam bersaing dengan khamir dan bakteri (Apriliana, 2017).

Berdasarkan Tabel 2 menunjukkan hasil uji analisa kapang yang sebesar 0 koloni/gram kemudian naik menjadi 7 koloni/gram pada sampel lama fermentasi biji kopi 8 jam, kemudian menurun hingga menjadi sebanyak 3 koloni/gram pada sampel biji kopi robusta dengan lama fermentasi 24 jam. Hasil uji kapang pada seluruh sampel kopi fermentasi disajikan pada Gambar 2.

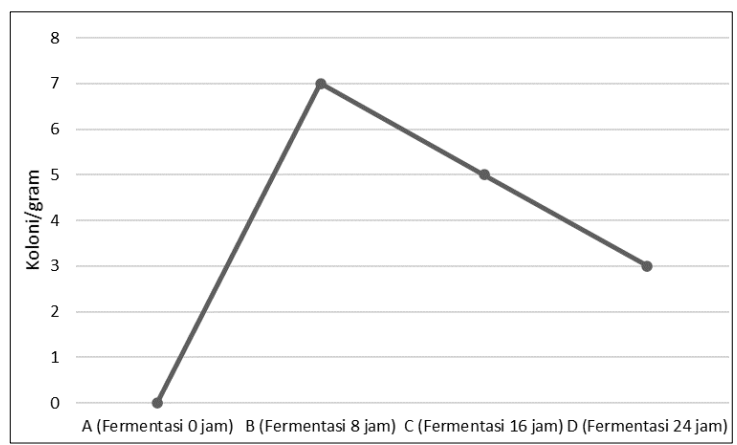

Gambar 2. Angka Kapang Biji Kopi Robusta Lampung Hasil Fermentasi

Hasil Analisa angka kapang pada biji kopi Robusta Lampung pada lama fermentasi biji kopi selama 8 jam yaitu 7 koloni/gram, kemudian menurun hingga menjadi sebanyak 3 koloni/gram pada sampel biji kopi robusta dengan lama fermentasi 24 jam meskipun kurang dari $10^{4}$ koloni/gram dari standar SNI 7388:2009 serta Perka BPOM tahun 2016 namun tetap menunjukkan pertumbuhan kapang pada produk biji kopi hasil fermentasi. Menurut Rasyidah (2018), kopi sebagai objek yang dapat dirusak oleh berbagai organisme, disebabkan mengandung nutrisi yang dibutuhkan oleh organisme untuk dapat tumbuh, namun yang sering menyerang kopi yaitu kapang. Hal ini dikarenakan produk kopi memiliki kadar air yang rendah. Kapang membutuhkan kadar air yang lebih rendah dibandingkan dengan bakteri. 
Pertumbuhan kapang dimungkinkan dipengaruhi oleh kandungan air yang terdapat dalam sampel biji kopi hasil fermentasi. Pada penelitian ini sangat erat dengan sampel yang di uji yaitu berupa bubuk kopi yang rentan terhadap kandungan air karena sifat dari bubuk kopi adalah higroskopis.

Kapang dapat tumbuh pada kopi yaitu apabila kadar air pada kopi melebihi standar yaitu lebih dari 12.5\% (BSN 2004). Kopi yang disimpan pada kondisi yang lembap dapat meningkatkan risiko tumbuhnya kapang. Selain kadar air yang mempengaruhi kontaminasi kapang pada kopi, jenis kemasan dapat mempengaruhi pertumbuhan kapang yang disebabkan kemampuan menahan keberadaan oksigen yang diperlukan kapang untuk tumbuh serta kemampuan kemasan tersebut untuk menjaga kelembapan (Muchtar et al. 2011)

Menurut Nasanit et al. (2015), kapang meskipun ditemukan dalam jumah sedikit yakni $4,7 \%$ (32 isolat) dari 681 isolat tapi keberadaaanya perlu diperhatikan secara serius karena beberapa kapang memproduksi mikotoksin yang sangat berbahaya bagi kesehatan. Genus kapang yang paling banyak mengontaminasi fermentasi biji kopi arabika (Coffea arabica) adalah Penicillium spp.

\section{Kesimpulan}

Semakin lama proses fermentasi mampu meningkatkan jumlah Total Bakteri. Hal ini dibuktikan dengan perhitungan Angka Lempeng Total (ALT) pada sampel Kopi D. Semakin lama proses fermentasi mampu menurunkan jumlah pertumbuhan kapang. Hal ini dibuktikan dengan perhitungan jumlah Kapang pada sampel B yang paling banyak pertumbuhan kapangnya.

\section{Daftar Pustaka}

Apriliana, A. (2017). Identifikasi jenis kapang pada biji kopi olahan perkebunan rakyat di Indonesia. Skripsi. Fakultas Teknologi Pertanian, Universitas Jember.

Asosiasi Eksportir Kopi Indonesia (AEKI) (2012). Industri Kopi Indonesia. http://www.aeki-aice.org/

Atmawinata, 0. (2002). Peranan uji citarasa dalam pengendalian mutu kopi. dalam Materi Pelatihan Uji Citarasa Kopi. Jember: Pusat Penelitian Kopi dan Kakao.

Badan Pengawas Obat dan Makanan (BPOM). (2016). Peraturan Kepala Badan Pengawas Obat dan Makanan Republik Indonesia Nomor 16 Tahun 2016 tentang Kriterian Mikrobiologi dalam Pangan
Olahan. Jakarta: Badan Pengawas Obat dan Makanan

Badan Standardisasi Nasional(BSN). (2004). SNI: 01-3542-2004 Kopi Bubuk. Jakarta: Badan Standardisasi Nasional.

Badan Standardisasi Nasional (BSN). (2004). SNI: 01-7388-2009. Batas Maksimum Cemaran Mikroba dalam Pangan. Jakarta: Badan Standardisasi Nasional.

Barlaman MBF, Suwasono S, Djumarti. (2013). Karakteristik fisik dan organoleptik biji kopi arabika hasil pengolahan semi basah dengan variasi jenis wadah dan lama fermentasi (studi kasus di Desa Padati dan Sukosawah Kabupaten Bondowoso). Jurnal Teknologi Industri Pertanian (AGROINTEK), 7(2):108-121.

Budryn, G., E. Nebesny, J. Kula, T. Majda, dan Krysiak, W. (2011). HS-SPME/GC/MS propiles of convectively and microwave roasted Ivory Coast Robusta coffee brews. Czech Journal of Food Sciences, 29 (2): 151-160.

Choiron, M. (2010). Penerapan GMP pada penanganan pascapanen kopi rakyat untuk menurunkan okratoksin produk kopi (studi kasus di Sidomulyo, Jember). Jurnal Teknologi Industri Pertanian (AGROINTEK), 4(2):114-120.

Direktorat Jendral Perkebunan. (2012) Perbaikan Mutu Kopi Indonesia. http://ditjenbun.deptan.go.id/

Ditjend PPHP. (2012). Peluang Besar Bisnis Kopi Indonesia. http://pphp.deptan.go.id/

Elliot, R.P. (1978). Microorganisme in Food, Their Significance and Methods of Enumeration, $2^{\text {nd }}$ G. Rotaru., N. Sava., D, Borda.,\& S. Stanciu. (2005). Food Quality and Safety Management Systems: A brief Analysis of The Individual and Integrated Approaches/ Scientifical Researches. Agroalimentary Processes and Technologies: Romania. Diakses dari: edition. ICSMF, Univeristy od Toronto Press. http://agris.fao.org/agrissearch/search.do?recordID=XF20150311 34

Fardiaz, S. (2004). Analisa Mikrobiologi Pangan. Jakarta: PT Raja Grafindo Persada. Diakses pada Perpustakaan Sido Muncul Semarang.

Hitokoto H, Morozumi S, Wauke T, Sakai, S. dan Ueno,I. (1978) Inhibitory effects of condiments and herbal drugs on the growth and toxin production of toxigenic fungi. Mycopathologia, 66, 161.

Khairani, D. (2017). Modifikasi ukuran cawan petri pada uji mikroba kopi bubuk dan 
kopi instan. Skripsi. Institut Pertanian Bogor, Bogor.

Martoyo, P. Haryadi, R \& Rahayu, W. (2014). Kajian standar cemaran mikroba dalam pangan di Indonesia. Jurnal Standardisasi, 16(2), 113 - 124.

Muchtar.H, Kamsina, dan Anova I.T. (2011). Pengaruh kondisi penyimpanan terhadap pertumbuhan jamur pada gambir. Jurnal Dinamika Penelitian Industri, 22(1), 3643.

Nasanit, R. dan Satayawut, K. (2015). Microbiological study during coffe fermentation of Coffea Arabica Var. Chiangmai 80 in Thailand. Kasetsart Journal Natural Science, 49, 32-42.

Pimenta, T. V., R. G. F. Pereira, J. L. G. Correa, and J. R. Silva (2009). Roasting processing of dry coffee cherry: influence of grain shape and temperature on physical chemical and sensorial grain properties. Boletim Centro de Pesquisa de Processamento de Alimentos Curitiba, 27 (1): 97-106.

Pusat Data dan Sistem Informasi Pertanian (PDSIP), Kementerian Pertanian (2015). Outlook Kopi: Komoditas Pertanian Subsektor Perkebunan. ISSN: 1907-1507.

Rasyidah, M. (2018). Keragaman kapang yang mengontaminasi kopi bubuk dan biji kopi sangrai akibat penyeduhan. Skripsi. Fakultas Teknologi Pertanian. Institut Pertanian Bogor, Bogor.

Sulistyaningtyas. A. R. (2017). Pentingnya pengolahan basah (wet processing) buah kopi robusta (Coffea robusta Lindl.ex.de.Will) untuk menurunkan risiko kecacatan biji hijau saat coffe grading. Prosiding Seminar Nasional Publikasi Hasil-Hasil Penelitian dan Pengabdian Masyarakat (pp.90-94). Semarang: Universitas Muhammadiyah Semarang.

Wang, N. (2012). Physicochemical changes of coffee beans during roasting. Thesis Master of Science University of Guelph. Ontario, Canada.

Widyotomo, S. dan Yusianto. (2013). Optimasi proses fermentasi biji kopi Arabika dalam fermentor terkendali. Pelita Perkebunan, 29(1): 53-68.

Yoni, A. (2016). Angka lempeng total (ALT), angka paling mungkin (APM), dan total kapang khamir sebagai metode analisis sederhana untuk menentukan standar mikrobiologi pangan olahan posdaya. Jurnal Teknologi, 8(2), 77 - 82. 